Supplement of Geosci. Model Dev., 14, 4249-4260, 2021

https://doi.org/10.5194/gmd-14-4249-2021-supplement

(C) Author(s) 2021. CC BY 4.0 License.

(c) (i)

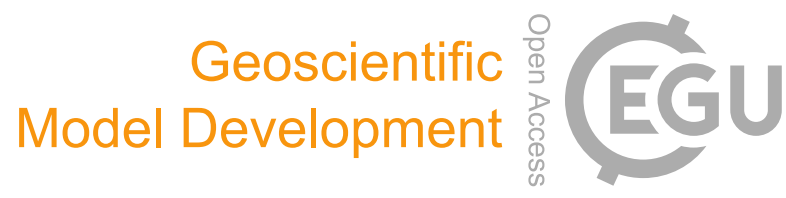

Supplement of

\title{
Grid-independent high-resolution dust emissions (v1.0) for chemical transport models: application to GEOS-Chem (12.5.0)
}

Jun Meng et al.

Correspondence to: Jun Meng (jun.meng@ucla.edu)

The copyright of individual parts of the supplement might differ from the article licence. 


\section{Supplement}

\section{S1. Description of the Dust Emission Parameterization}

The dust detrainment and deposition (DEAD) scheme (Zender et al., 2003) is based on a theory studying the transport of dust by winds by White (1979) to calculate horizontal dust saltation flux $H$ :

$$
H=C \frac{\rho}{g} U^{* 3}\left(1-\frac{U_{t}^{*}}{U^{*}}\right)\left(1+\frac{U_{t}^{*}}{U^{*}}\right)^{2}
$$

where $C$ is a global tuning factor determining the total dust strength, $\rho$ is the air density, $g$ is the acceleration of gravity, $U^{*}$ is the friction velocity and $U_{t}^{*}$ is the threshold friction velocity. The vertical dust flux $F$, is proportional to the horizontal saltation flux $F$ is parameterized as:

$$
F=A_{m} S \alpha H
$$

where $\alpha$ is the sandblasting mass efficiency, which is a function of the clay fraction in the soil. We use a fixed soil clay fraction of 0.2 as suggested in Zender et al. (2003). $S$ is dust source function, which is an effective factor that favors emissions from specific geographic features. We updated $S$ with a fine resolution dataset without vegetation mask as described in Sect. S2. $A_{m}$ is a factor that suppresses dust emissions from snow covered land $\left(A_{s}\right)$, wetlands $\left(A_{i}\right)$ and water bodies $\left(A_{w}\right)$ and vegetated area $\left(A_{v}\right)$,

$$
A_{m}=\left(1-A_{s}\right)\left(1-A_{i}-A_{w}\right)\left(1-A_{v}\right)
$$

The vegetation effect $A_{v}$ is represented by monthly mean leaf plus stem area index (LAI) following Zender et al. (2003). This feature enables seasonal dust mobilization in the dust emisison scheme. We have not investigated interannual vegetation variation in this study. 


\section{S2. Description of the Updated Source Function}

The updated source function provides erodibility factors for sparsely vegetated surfaces with a potential for accumulated fine sediments. The potential location of accumulated sediments has been determined by comparing the elevation of any $1 \times 1$ degree grid point with its surrounding hydrological basin using the same equation 1 of Ginoux et al. (2001). The updated source function is then linearly interpolated to a 0.25 degree Cartesian grid and multiplied by the fraction of bare surface within the grid cell. Such surfaces are obtained globally from the classes 8 (bare ground) and 9 (shrubs and bare ground) of the land cover inventory retrieved from the multi-year $8 \mathrm{~km}$ AVHRR data (Defries et al., 2000). It is assumed that 100\% of class 8 is bare, while only $20 \%$ for class 9 . According to the survey by the Chinese Academy of Sciences (CAS, 1998), desertification has increased the bare sandy lands in China. To include these barren lands, we follow the methodology followed by Gong et al. (2003) to use the Chinese Desertification Map (Sunling Gong personal communication) and consider the desertification classes 1 (serious desertification soil), 2 (heavy desertification soil), 3 (current desertification soil) with $80 \%$ erodible bare surface, and classes 4 (potential desertification soil) and 5 (lowgrade desertification soil) with $60 \%$ erodible bare surface. 


\section{Supplemental Figures}

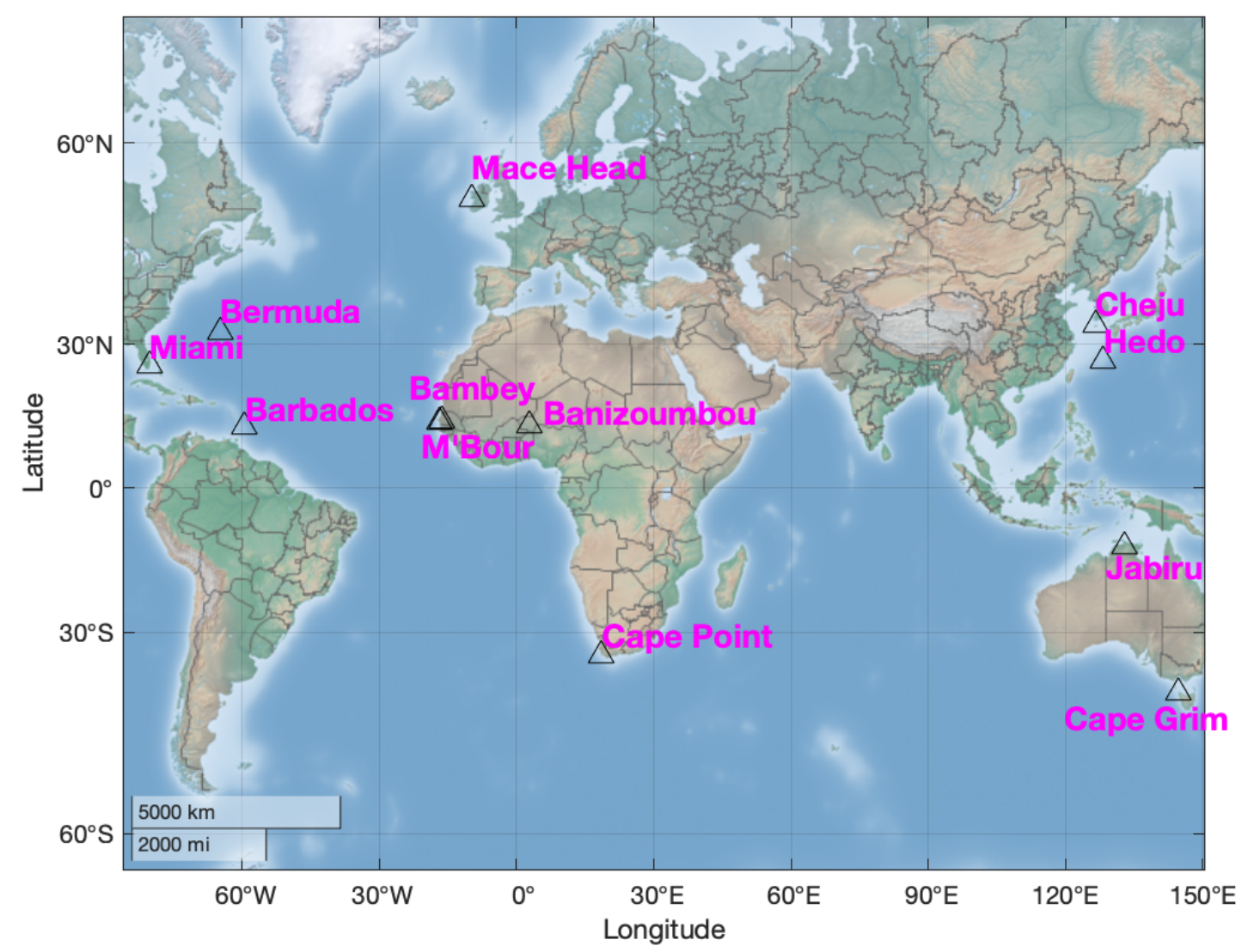

Figure S1. Geolocations of the 12 independent sites used in Figure 6 of the main text. 


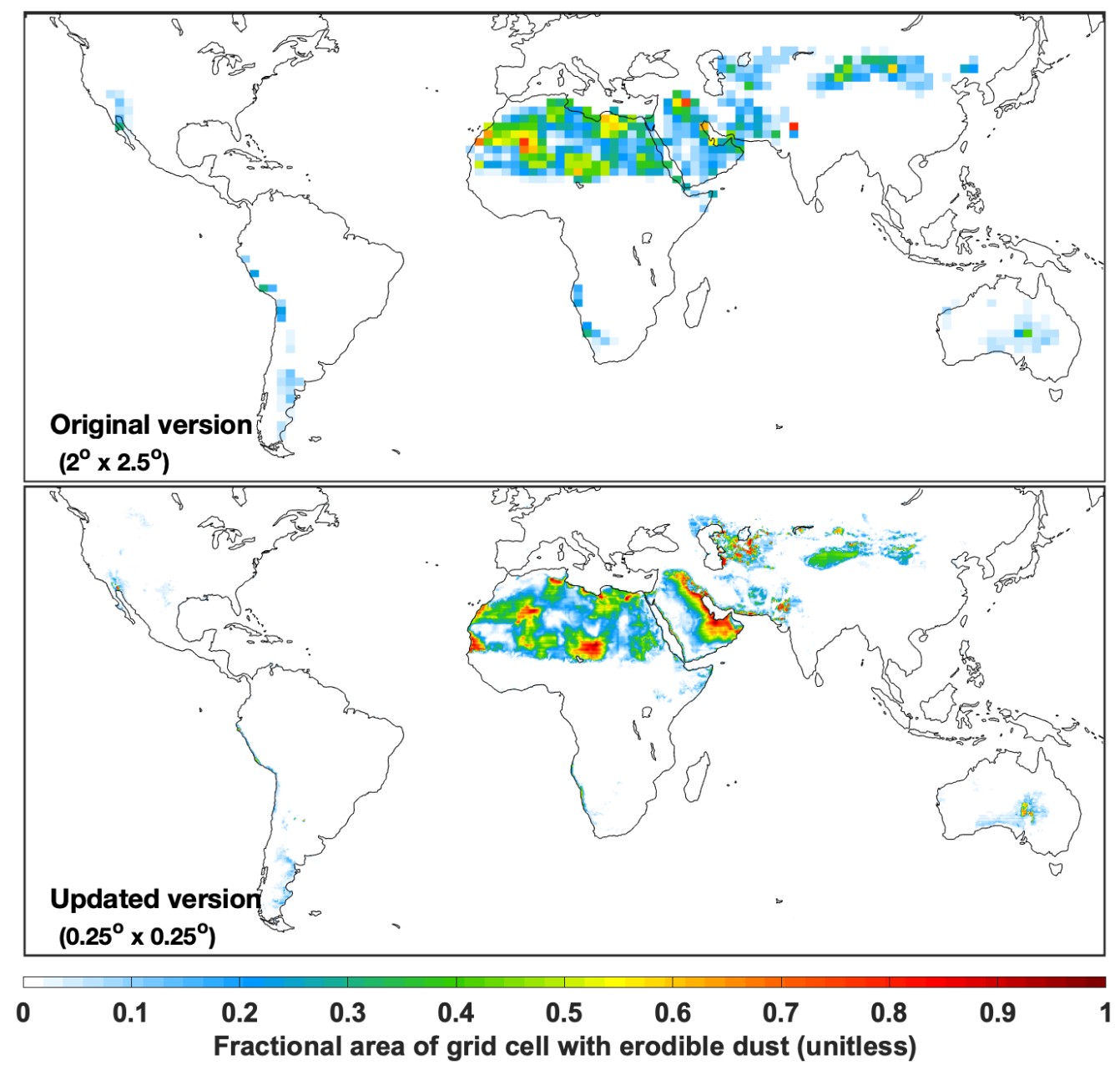

Figure S2. The original and updated versions of the dust source function. 

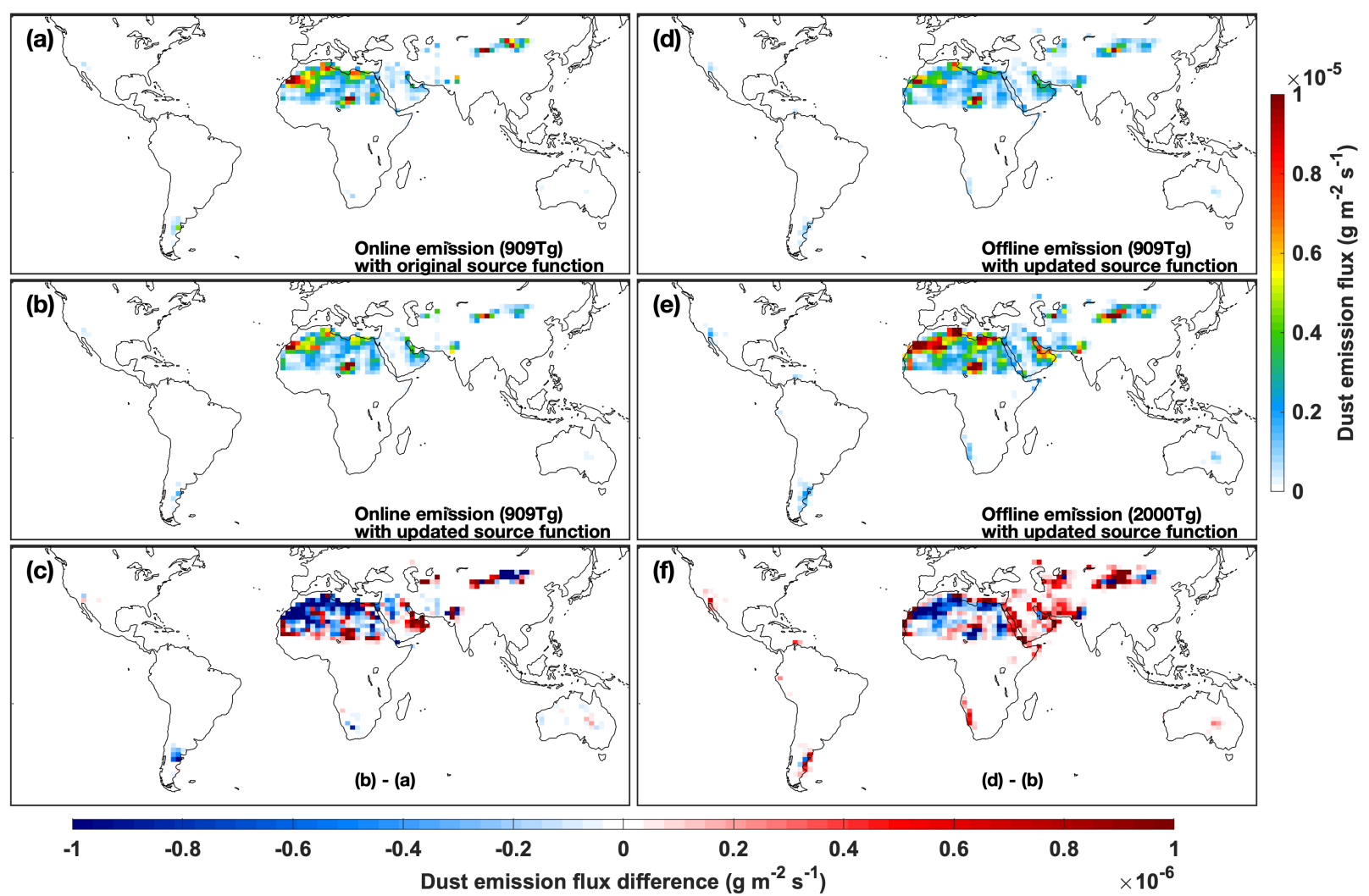

Figure S3. As in Fig. 2 but averaged over MAM (March, April and May). 

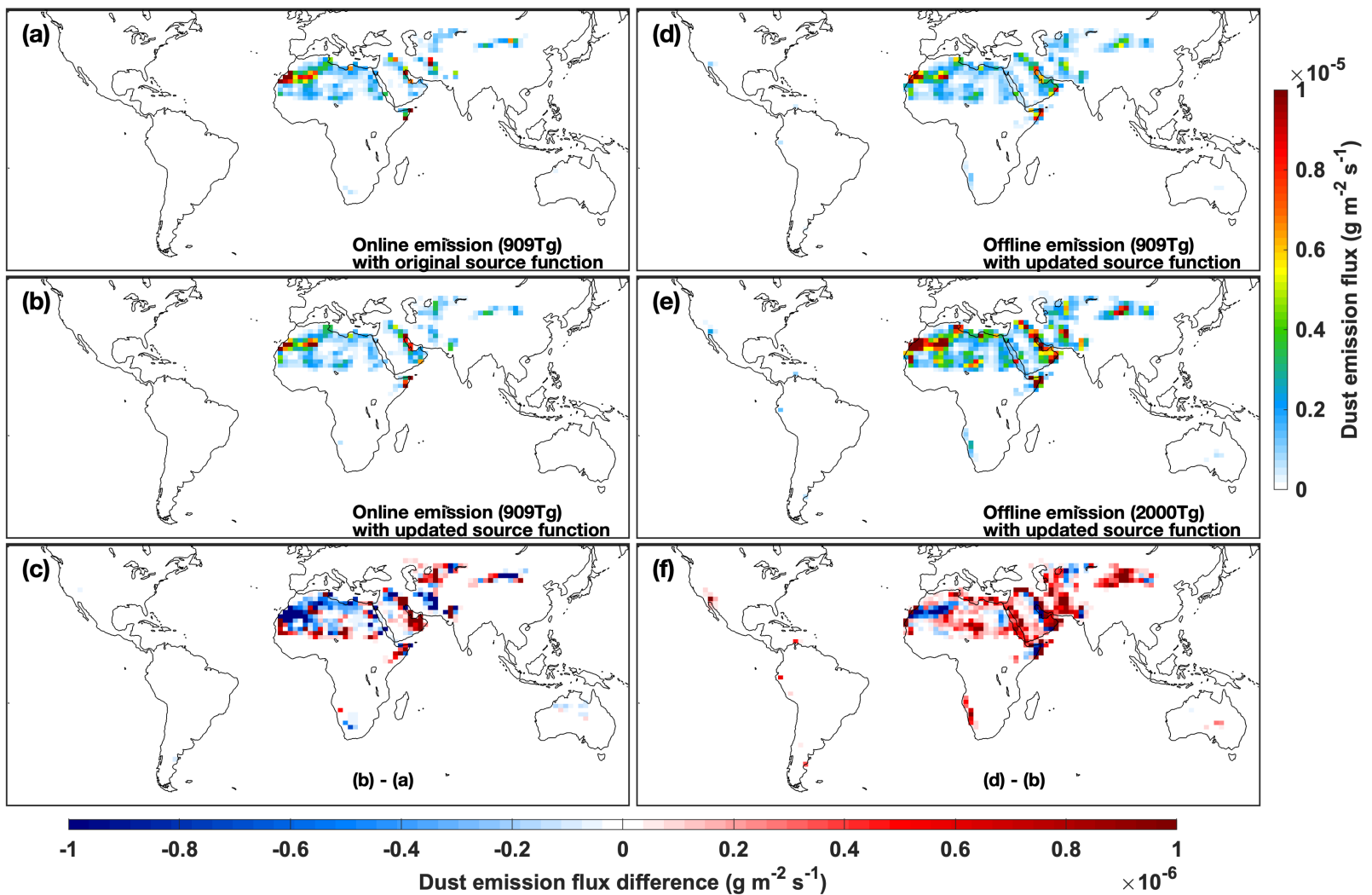

Figure S4. As in Fig. 2 but averaged over JJA (June, July and August).
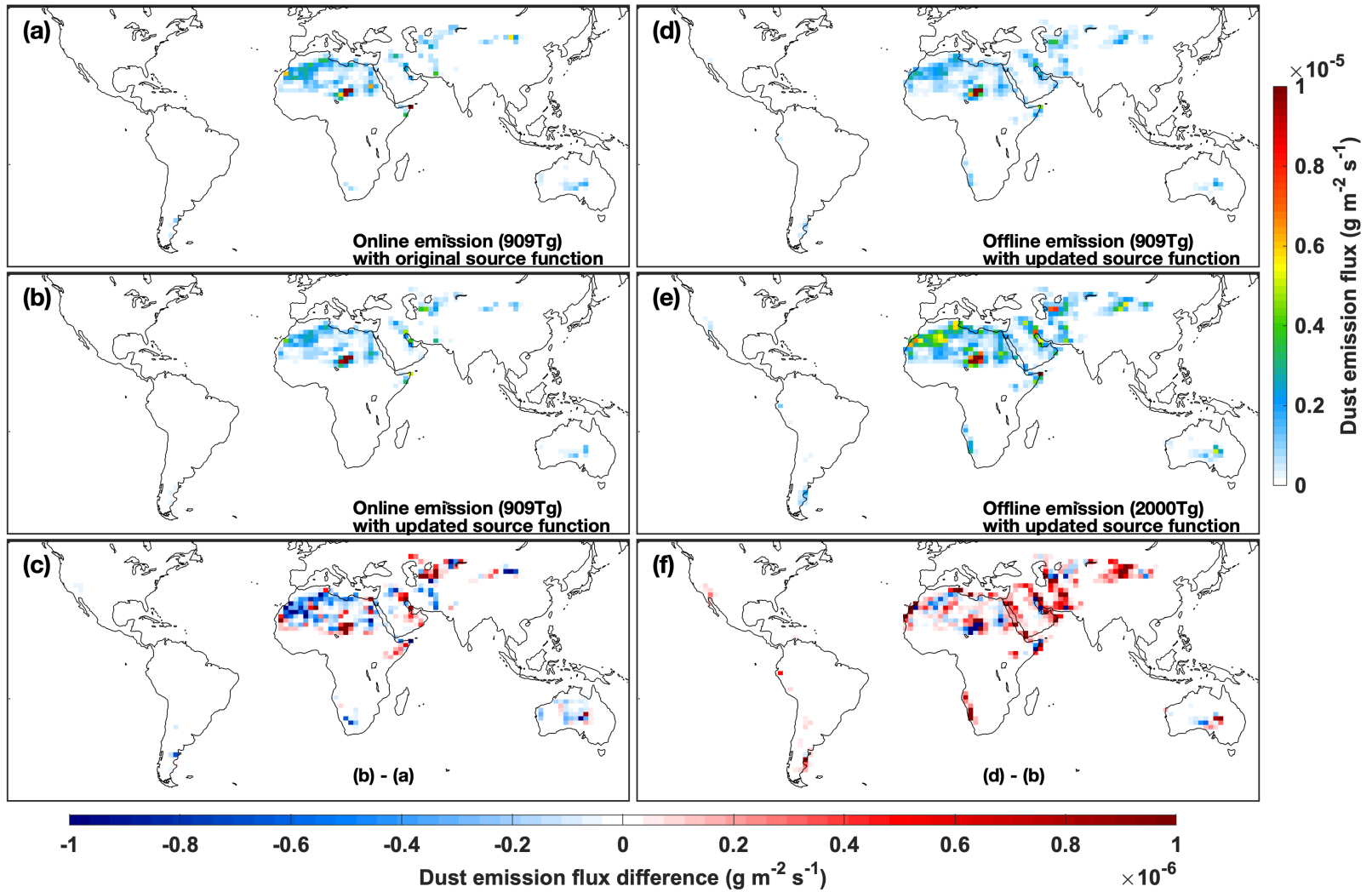

Figure S5. As in Fig. 2 but averaged over SON (September, October and November). 

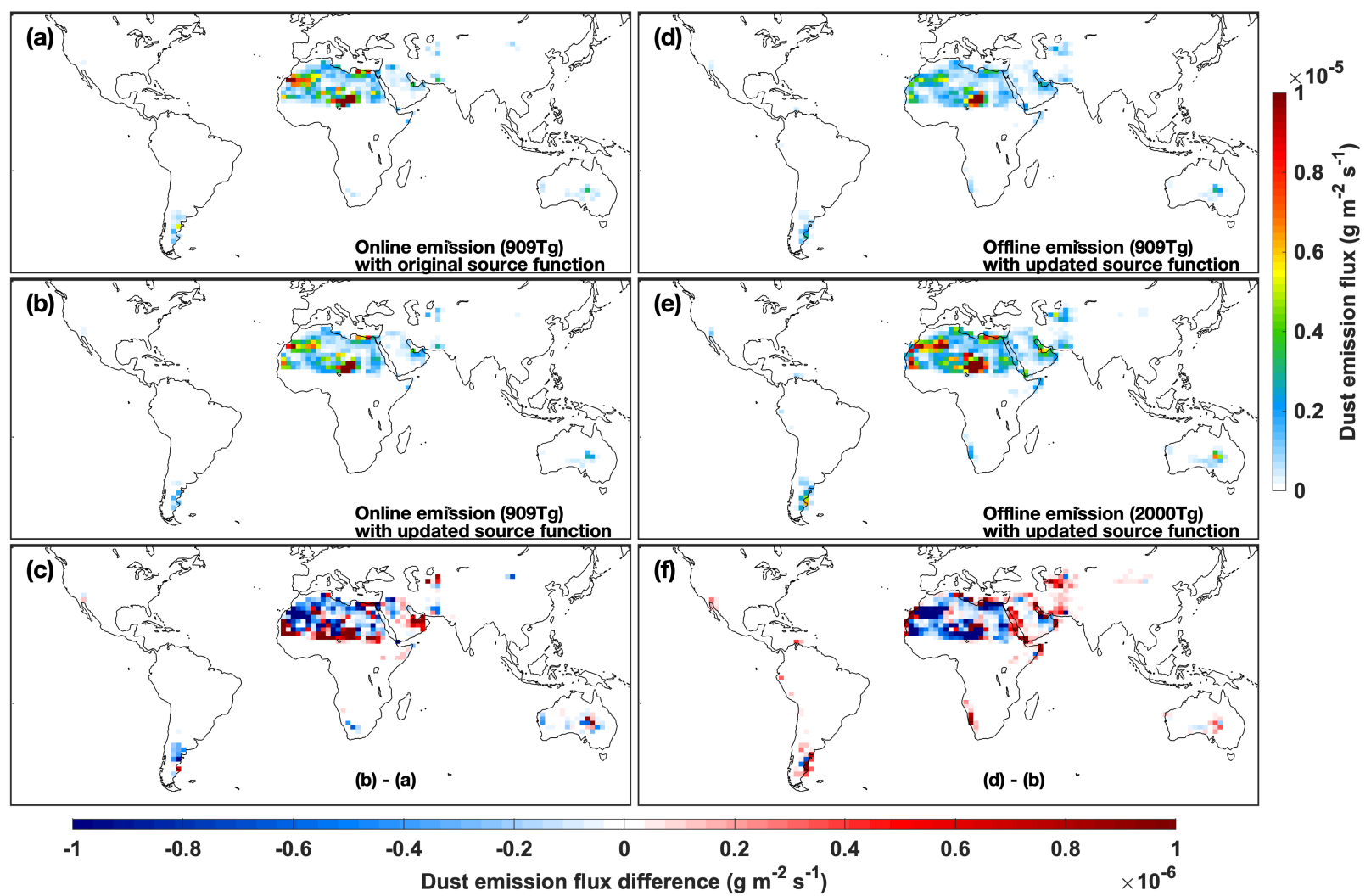

Figure S6. As in Fig. 2 but averaged over DJF (December, January and February). 

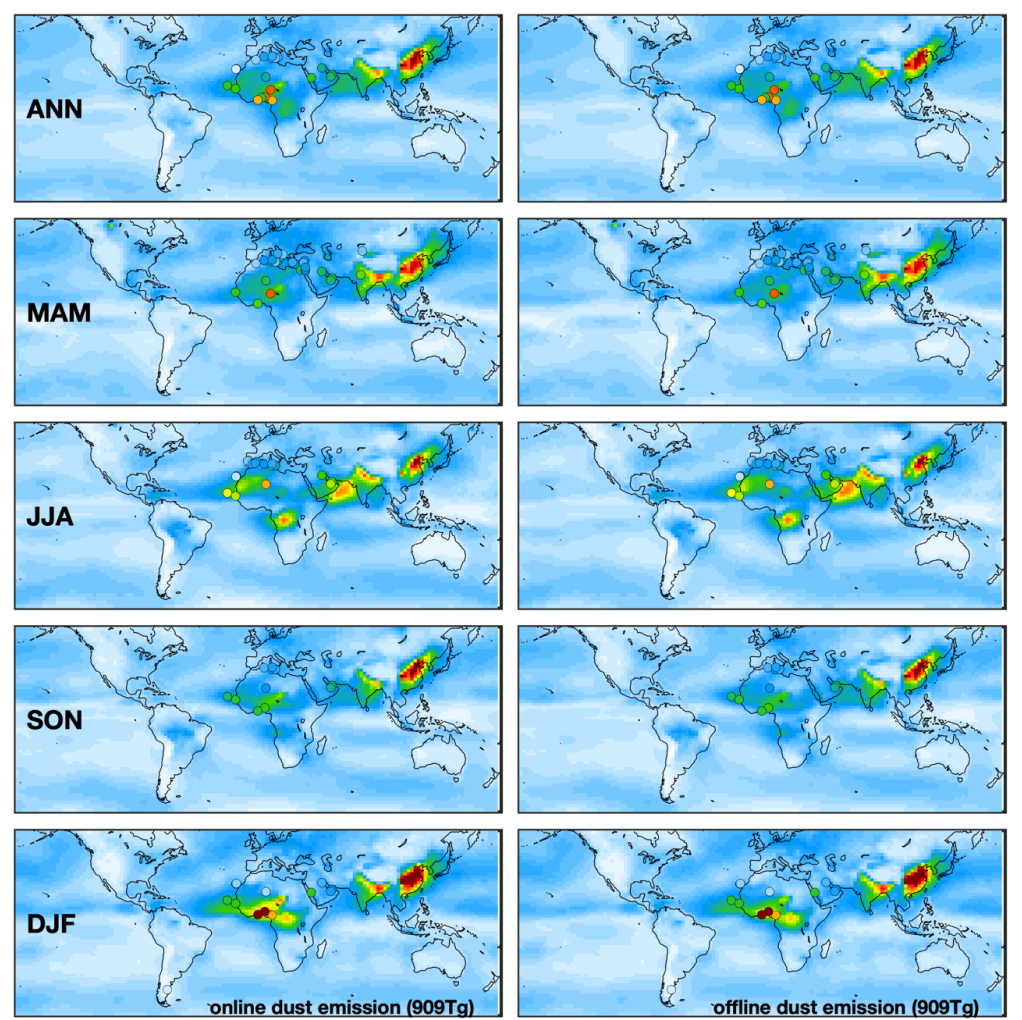

$\mathbf{0}$

0.8
$0.2 \quad 0.4$

0.6

s)
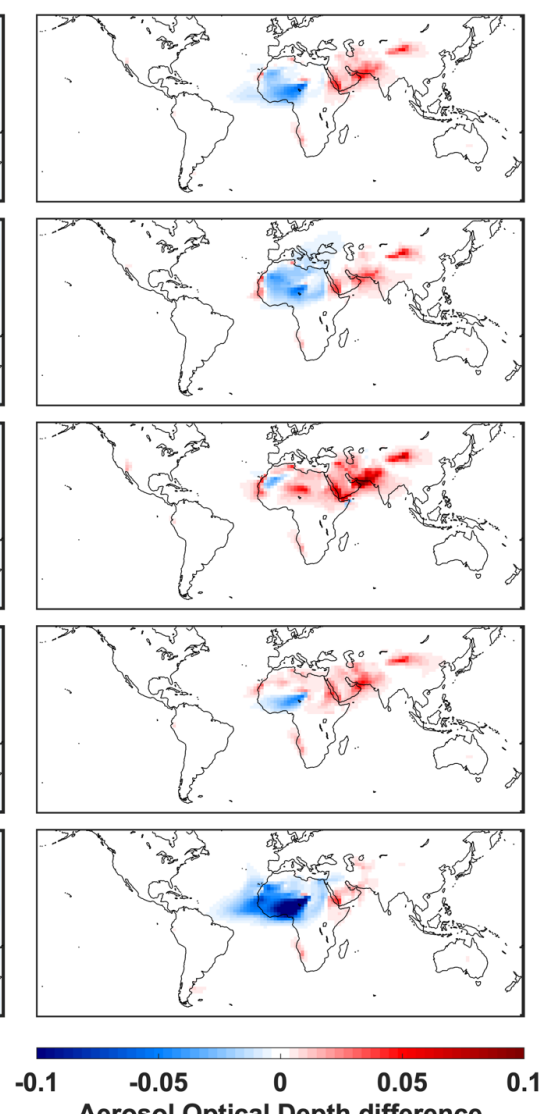

Figure S7. Spatial distribution of simulated AOD from simulations using the online dust emissions (left column) and offline dust emissions (middle column) that were with the same updated dust source function and the same annual dust strength (909 Tg), and the AOD differences between those two simulations (right column) in different seasons. Filled circles represent the AERONET measurements included in Figure 3. 

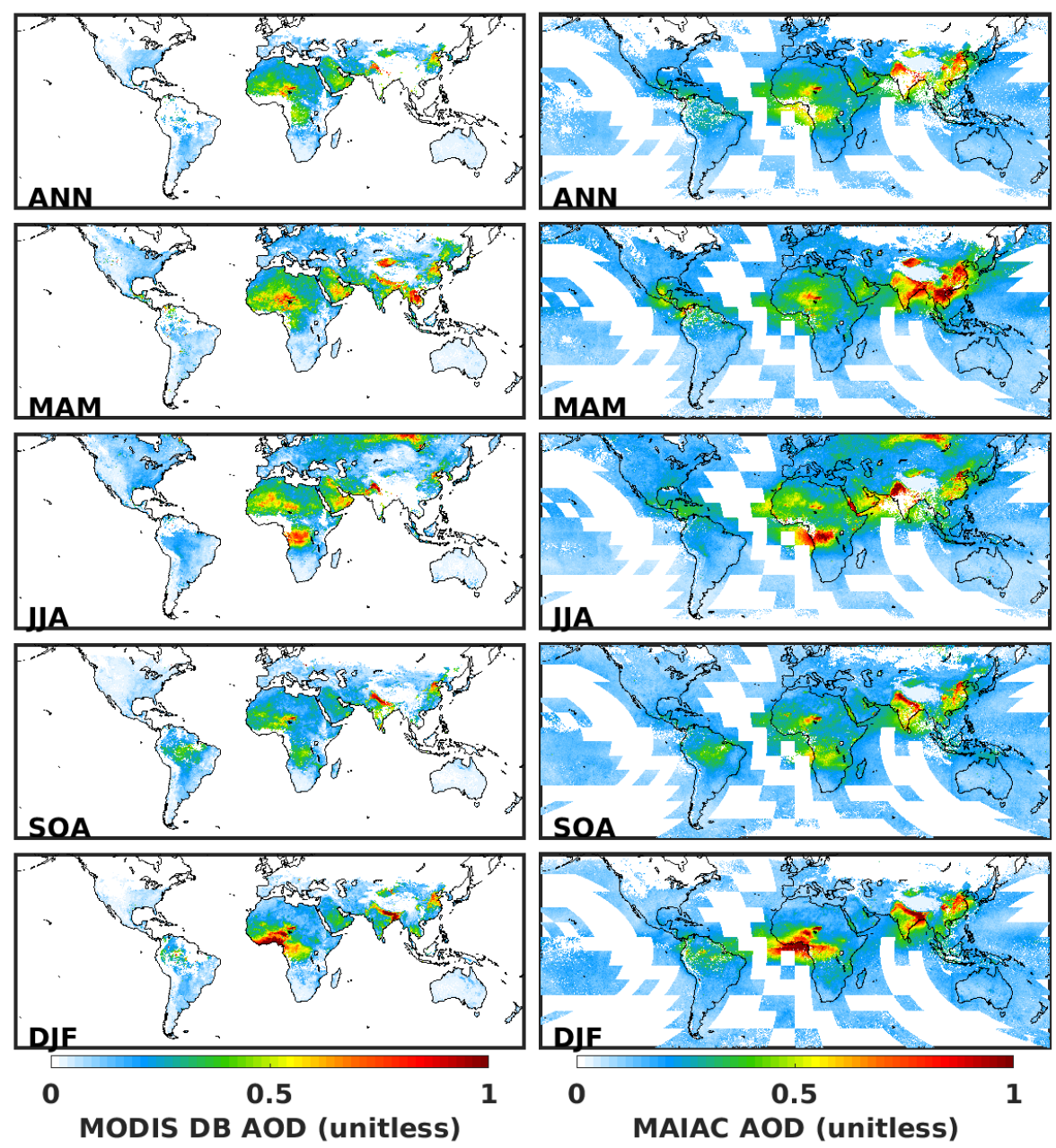

Figure S8. Annual and seasonal satellite AOD from MODIS Deep Blue (DB) and MAIAC algorithms. 


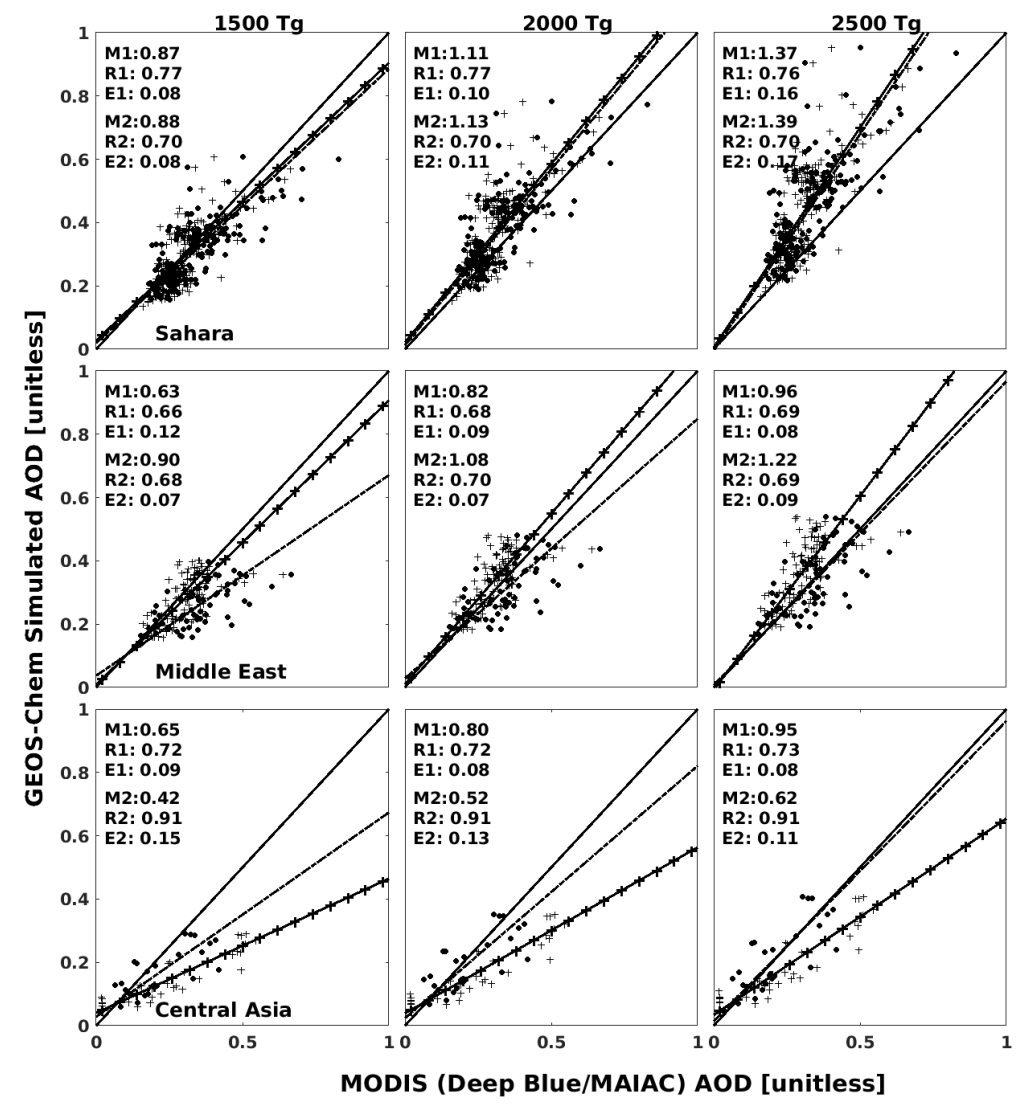

Figure S9. Scatter plots and statistics of comparing GEOS-Chem simulated annual mean AOD with satellite AOD over desert regions. Three columns represent three simulations with total annual dust emissions scaled to the value of 1,500 Tg, 2,000 Tg and 2,500 Tg respectively. The results for North African, Middle East and central Asian deserts are shown in the top, middle and bottom rows respectively. Dots represent the comparison with MODIS Deep Blue AOD; the plus signs represent the comparison with MAIAC AOD. Correlation coefficient (R), root mean square error (E), and Slope (M) are reported, in which R1, E1 and M1 show the results of the comparison with MODIS Deep AOD; R2, E2 and $\mathrm{M} 2$ show the results of the comparison with MAIAC AOD. The best fit lines are lines with corresponding marker signs. The 1:1 line solid black line. 

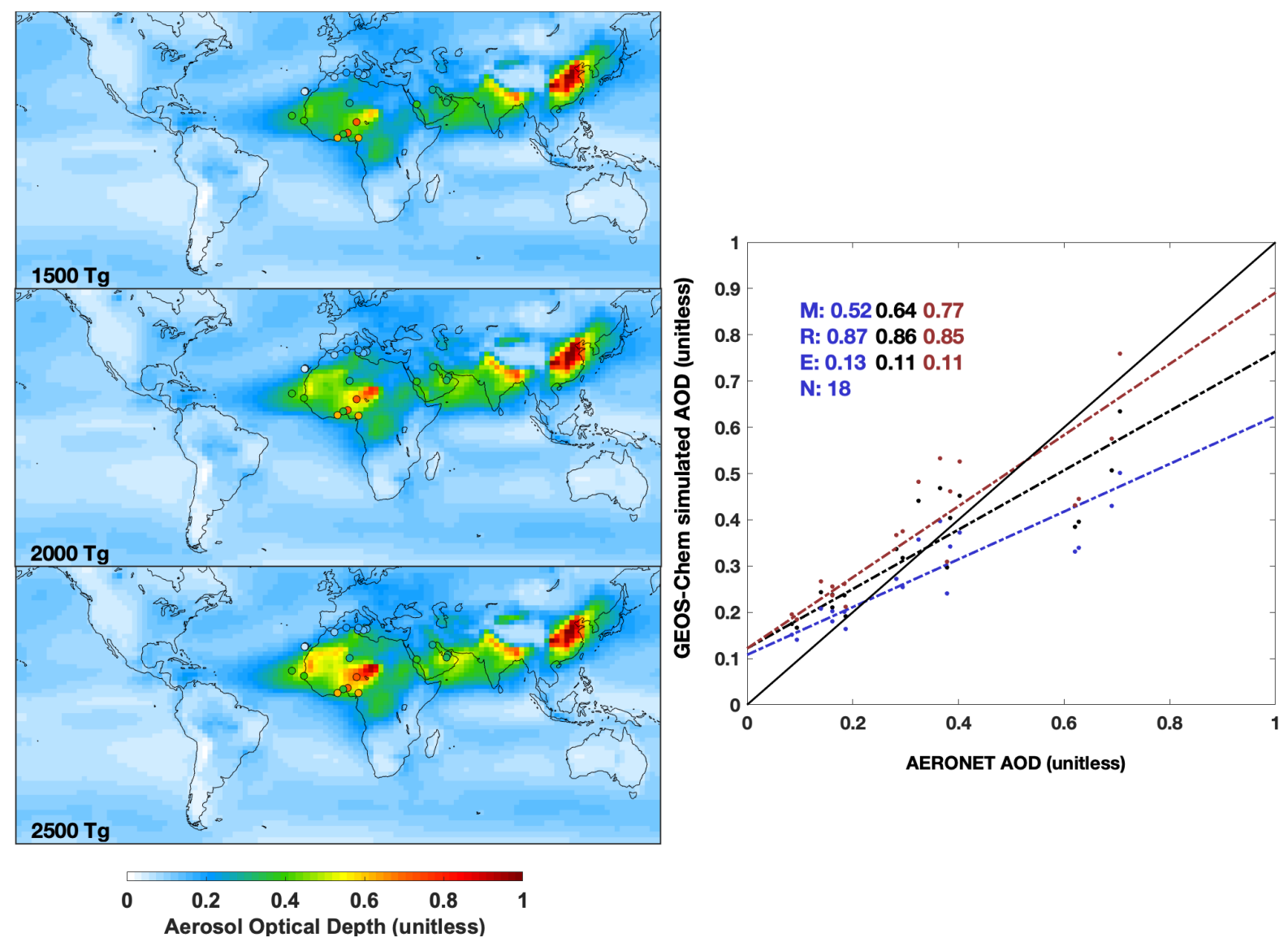

Figure S10. Annual mean simulated aerosol optical depth (AOD) from GEOS-Chem simulations for 2016 for simulations with total annual dust emissions of 1,500 Tg, 2,000 Tg and 2,500 Tg, and the comparison against AERONET measured AOD. Sites, shown as filled circles are chosen by where the ratio of simulated DOD and AOD exceeds 0.5 . Corresponding statistics, including root mean square error (E), correlation coefficient $(\mathrm{R})$ and slope $(\mathrm{M})$, are inset. Blue, black and red in the scatter plot represent simulations with total annual dust emissions of 1,500 Tg, 2,000 Tg and 2,500 Tg, respectively. 


\section{References}

Chinese Academy of Sciences, Chinese Desertification Map, Resource and Environment Database, Beijing, 1998.

Defries, R. S., Hansen, M. C. and Townshend, J. R. G.: Global continuous fields of vegetation characteristics: A linear mixture model applied to multi-year $8 \mathrm{~km}$ AVHRR data, International Journal of Remote Sensing, 21(6-7), 1389-1414, https://doi.org/10.1080/014311600210236, 2000.

Ginoux, P., Chin, M., Tegen, I., Prospero, J. M., Holben, B., Dubovik, O. and Lin, S.-J.: Sources and distributions of dust aerosols simulated with the GOCART model, Journal of Geophysical Research: Atmospheres, 106(D17), 20255-20273, https://doi.org/10.1029/2000JD000053, 2001.

Gong, S. L., Zhang, X. Y., Zhao, T. L., McKendry, I. G., Jaffe, D. A. and Lu, N. M.: Characterization of soil dust aerosol in China and its transport and distribution during 2001 ACE-Asia: 2. Model simulation and validation, Journal of Geophysical Research: Atmospheres, 108(D9), https://doi.org/10.1029/2002JD002633, 2003.

White, B. R.: soil transport by winds on Mars, Journal of Geophysical Research: Solid Earth, 84(B9), 4643-4651, https://doi.org/10.1029/JB084iB09p04643, 1979.

Zender, C. S., Bian, H. and Newman, D.: Mineral Dust Entrainment and Deposition (DEAD) model: Description and 1990s dust climatology, Journal of Geophysical Research: Atmospheres, 108(D14), https://doi.org/10.1029/2002JD002775, 2003. 